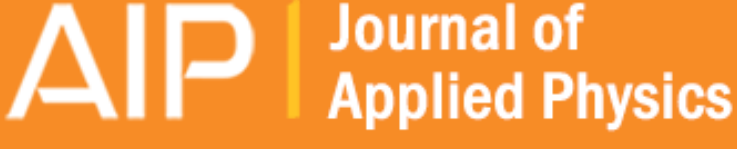

Temperature-dependent mechanical deformation of silicon at the nanoscale: Phase transformation versus defect propagation

M. S. R. N. Kiran, T. T. Tran, L. A. Smillie, B. Haberl, D. Subianto, J. S. Williams, and J. E. Bradby

Citation: Journal of Applied Physics 117, 205901 (2015); doi: 10.1063/1.4921534

View online: http://dx.doi.org/10.1063/1.4921534

View Table of Contents: http://scitation.aip.org/content/aip/journal/jap/117/20?ver=pdfcov

Published by the AIP Publishing

\section{Articles you may be interested in}

Phase transformation as the single-mode mechanical deformation of silicon

Appl. Phys. Lett. 106, 252103 (2015); 10.1063/1.4923205

Temperature dependent deformation mechanisms in pure amorphous silicon

J. Appl. Phys. 115, 113511 (2014); 10.1063/1.4869136

Deformation mechanisms in silicon nanoparticles

J. Appl. Phys. 109, 063534 (2011); 10.1063/1.3552985

Effect of hydrogen on nanoindentation-induced phase transformations in amorphous silicon

J. Appl. Phys. 106, 123511 (2009); 10.1063/1.3267853

Rate-dependent phase transformations in nanoindented germanium

J. Appl. Phys. 105, 126101 (2009); 10.1063/1.3151967

Frustrated by

old technology?

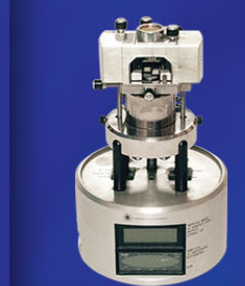

Is your AFM dead

and can't be repaired?

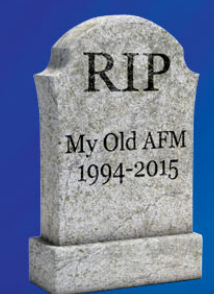

Sick of bad customer support?

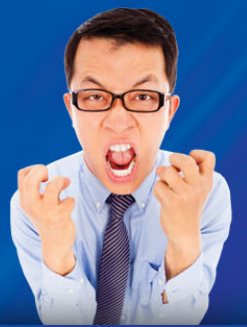

It is time to upgrade your AFM

Minimum $\$ 20,000$ trade-in discount for purchases before August 31st

Asylum Research is today's technology leader in AFM

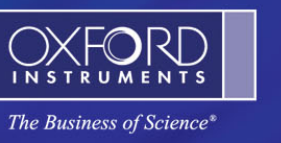




\title{
Temperature-dependent mechanical deformation of silicon at the nanoscale: Phase transformation versus defect propagation
}

\author{
M. S. R. N. Kiran, ${ }^{1, a)}$ T. T. Tran, ${ }^{1}$ L. A. Smillie, ${ }^{1}$ B. Haberl, ${ }^{1,2}$ D. Subianto, ${ }^{1}$ J. S. Williams, ${ }^{1}$ \\ and J. E. Bradby ${ }^{1}$ \\ ${ }^{1}$ Department of Electronic Materials Engineering, Research School of Physics and Engineering, \\ Australian National University, Australian Capital Territory, Canberra 2601, Australia \\ ${ }^{2}$ Chemical and Engineering Materials Division, Oak Ridge National Laboratory, Oak Ridge, \\ Tennessee 37831, USA
}

(Received 24 February 2015; accepted 9 May 2015; published online 27 May 2015)

\begin{abstract}
This study uses high-temperature nanoindentation coupled with in situ electrical measurements to investigate the temperature dependence $\left(25-200^{\circ} \mathrm{C}\right)$ of the phase transformation behavior of diamond cubic (dc) silicon at the nanoscale. Along with in situ indentation and electrical data, ex situ characterizations, such as Raman and cross-sectional transmission electron microscopy, have been used to reveal the indentation-induced deformation mechanisms. We find that phase transformation and defect propagation within the crystal lattice are not mutually exclusive deformation processes at elevated temperature. Both can occur at temperatures up to $150{ }^{\circ} \mathrm{C}$ but to different extents, depending on the temperature and loading conditions. For nanoindentation, we observe that phase transformation is dominant below $100^{\circ} \mathrm{C}$ but that deformation by twinning along $\{111\}$ planes dominates at $150{ }^{\circ} \mathrm{C}$ and $200^{\circ} \mathrm{C}$. This work, therefore, provides clear insight into the temperature dependent deformation mechanisms in dc-Si at the nanoscale and helps to clarify previous inconsistencies in the literature. (C) 2015 AIP Publishing LLC. [http://dx.doi.org/10.1063/1.4921534]
\end{abstract}

\section{INTRODUCTION}

The application of high pressures is known to induce a variety of other crystalline structures in silicon ${ }^{1}$ accompanied by significant changes in mechanical, ${ }^{2}$ electronic, ${ }^{3}$ and optical properties. ${ }^{4}$ Both diamond anvil cells (DAC) ${ }^{5-9}$ and theoretical studies ${ }^{10}$ have revealed that the standard diamond cubic (dc) Si transforms to a metallic phase with $\beta$-Sn structure at a pressure of $\sim 11-13 \mathrm{GPa}$. A subsequent pressure release facilitates the formation of a rhombohedral (r8) phase at $\sim 9 \mathrm{GPa}$ and a body-centred-cubic (bc8) phase at $\sim 2 \mathrm{GPa}^{8,9}$ The $\mathrm{r} 8$ phase of silicon has been identified as a narrow band gap indirect semiconductor and may be useful for photovoltaic applications. ${ }^{11,12}$ In addition, the lower etching rates of the $\mathrm{r} 8 / \mathrm{bc} 8$ phases have potential for applications involving a maskless patterning process. ${ }^{13}$

Indentation with a micro/nanoscale tip is known to induce similar phase transformations in dc-Si at ambient temperature. ${ }^{2,14-16}$ In addition to the formation of a mixture of the $\mathrm{r} 8 / \mathrm{bc} 8$ phases, fast unloading from the $(\beta-\mathrm{Sn})-\mathrm{Si}$ phase formed via indentation can result in the formation of an amorphous phase. ${ }^{17}$ Recent studies by Gerbig et al. ${ }^{18-20}$ reported the simultaneous formation of $\mathrm{r} 8$ and bc 8 phases from the metallic $\beta$-Sn phase during unloading using an in-situ Raman microscopy set-up. The above literature has focused on understanding the indentation-induced phase transformation behaviour of crystalline $\mathrm{Si}$ at room temperature (RT), and knowledge on the temperature dependence of such transformations remains limited, despite the obvious technological significance of such mechanisms. ${ }^{21}$

a)kiran.mangalampalli@anu.edu.au
Previously, studies of the temperature dependence of phase transformation have primarily utilized larger-scale micro-indentation techniques. In 1972, Gridneva et al. ${ }^{16}$ showed that a dc-Si to $\beta$-Sn phase transformation can occur under micro-indentation up to $370^{\circ} \mathrm{C}$ using electrical resistance measurement. Consistent with this finding, Gilman ${ }^{22}$ argued that up to the Debye temperature, $\theta_{D}\left(\sim 372^{\circ} \mathrm{C}\right)$, phase transformation is the dominant mode of plastic deformation in single crystal $\mathrm{Si}$ followed by brittle fracture above certain loads. Beyond $\theta_{D}$ defect propagation in the form of dislocation activity dominates. This was to some extent confirmed by further experiments that reported plastic deformation under the indenter results in phase transformation up to $500{ }^{\circ} \mathrm{C}{ }^{23}$ Beyond that temperature, plastic deformation resulted from dislocation activity (dislocation glide).

In contrast to the above studies, an intermediate regime has also been observed between phase transformation and dislocation glide. ${ }^{24}$ Between $350{ }^{\circ} \mathrm{C}$ and $650{ }^{\circ} \mathrm{C}$, another form of defect propagation, namely, twinning, under the diamond pyramidal microindenter along the $\{111\}$ plane, was observed alongside the lonsdaleite/hexagonal-diamond structure of Si (hd-Si). This hd-Si phase was first reported in 1963 and forms via annealing of the bc 8 phase made in a DAC. ${ }^{25}$ Note that the r8 phase transforms directly to dc-Si (Ref. 26) on annealing at a temperature of $255^{\circ} \mathrm{C}$ while pressureinduced amorphous $\mathrm{Si}$ (PI $a$-Si) relaxes to a continuous random network, ${ }^{27}$ which in turn also transforms directly to dc$\mathrm{Si}$ at temperatures typically higher than $450{ }^{\circ} \mathrm{C} .{ }^{28}$ Similarly, Pirouz et al. ${ }^{29}$ also observed formation of hd-Si during micro-indentation in the temperature range of $450-650{ }^{\circ} \mathrm{C}$ alongside twinning of dc-Si. However, in contrast, other experiments at similar temperatures did not observe the 
presence of hd-Si, but instead the sole presence of twin bands. 30,31

In 2008, Domnich et al. ${ }^{32}$ reported that the dc-Si phase transforms to $\beta$-Sn during large load Vickers indentation up to $300{ }^{\circ} \mathrm{C}$ but that dislocation glide becomes the dominant mode of deformation beyond $350^{\circ} \mathrm{C}$. In addition, they also reported the formation of a $\mathrm{Si}^{-\mathrm{XIII}^{33}}$ phase (structure remains unknown) at the higher temperature of $200^{\circ} \mathrm{C}$.

Thus, it is clear that the literature in this field contains inconsistencies. Indeed, it is currently impossible to answer the fundamental question "how exactly does Si mechanically deform at elevated temperatures?"

We believe that the inconsistencies in the above studies are due primarily to size-effects, in particular, specially indenter size and the resulting maximum load and loading rate effects. Indeed, using large Vickers macro/micro indentation, the full load ( $\sim 10$ to $200 \mathrm{~N}$ ) will be applied very quickly. ${ }^{34}$ Such fast loading conditions can activate other modes of plastic deformation and fracture under the indenter since the rate of change of stress gradients increases dramatically. This complicates the estimation of the exact transition temperature and dominant deformation mechanism under such large scale indenters where multiple plasticity modes and fracture can occur simultaneously. In contrast, nanoindentation experiments have the advantage of controlled application of relatively small forces $(\leq 10 \mathrm{mN})$ and the real-time monitoring of indenter penetration depth with high precision and accuracy. ${ }^{35}$ Additionally, the load $(P)$-displacement $(h)$ curves during indentation provide signature responses that can be related to the mode of deformation under the indenter, such as the so-called "pop-in" events during loading, "popout" events, and "elbowing" during unloading.

Thus, although much has been reported on in-situ nanoindentation-induced phase transformations in dc-Si at RT, ${ }^{14,17-20}$ in-situ studies are limited only to a few studies. ${ }^{36-38}$ at elevated temperatures. One study has investigated the deformation of $\mathrm{Si}$ at temperatures of $20-135^{\circ} \mathrm{C}$ and reported at $135^{\circ} \mathrm{C}$, an unidentifiable phase, along with the possibility of a tetragonal form of Si on unloading. ${ }^{36}$ However, other work at similar temperatures $\left(25-150^{\circ} \mathrm{C}\right)$ on both dc-Si and relaxed amorphous $\mathrm{Si}$ found instead that the probability of formation of the bc8/r8 phases was enhanced during unloading with increasing temperature. ${ }^{37}$ Interestingly, for slow unloading $(0.2 \mathrm{mN} / \mathrm{s})$ at $125^{\circ} \mathrm{C}$, no formation of bc8/r8 was observed. Finally, it has been also suggested that the $\beta$-Sn phase is unstable in a dc-Si matrix at elevated temperatures and may directly transform to dc-Si during the early stages of unloading. ${ }^{38}$ Thus, the deformation mechanisms of $\mathrm{Si}$ at small scales and elevated temperatures remains unclear.

In this current study, in-situ high temperature nanoindentation (up to $200^{\circ} \mathrm{C}$ ) is used to indent dc-Si and ex-situ characterization techniques, such as Raman and crosssection transmission electron microscopy (XTEM), are used to characterize the residual indents. In addition, electrical measurements during indentation have been carried out to reveal the onset of indentation-induced phase transformations from dc-Si to the metallic $(\beta-\mathrm{Sn})$ phase at various temperatures.

\section{EXPERIMENTAL DETAILS}

\section{A. Nanoindentation}

Nanoindentation was performed on Czochralski grown $\mathrm{Si}$ (100) wafers $p$-doped with boron to a resistivity of 10-20 $\Omega$ $\mathrm{cm}$, using a TI 950 Hysitron Triboindenter (Minneapolis, USA). A three-sided diamond pyramidal Berkovich tip with an end radius of $\sim 100 \mathrm{~nm}$ was used in this study. Indentations were performed at $25,50,100,150$, and $200^{\circ} \mathrm{C}$ on a heating stage, which has a maximum temperature of $300{ }^{\circ} \mathrm{C} .{ }^{39,40}$ Loading was performed in $10 \mathrm{~s}$ to reach a peak load of $P_{\text {max }}=10 \mathrm{mN}$ and unloading was performed at a fast and a slow rate of 10 and $0.2 \mathrm{mN} \mathrm{s}^{-1}$, respectively. A hold period of $5 \mathrm{~s}$ was applied at $P_{\max }$. In addition, to investigate the effect of the loading rate on the deformation behaviour of $\mathrm{dc}-\mathrm{Si}$, a Berkovich tip was loaded also within $0.1 \mathrm{~s}$ and $1 \mathrm{~s}$ to $P_{\text {max }}=10 \mathrm{mN}$ and with an unloading rate of $0.2 \mathrm{mN} / \mathrm{s}$. Furthermore, a conospherical indenter with a radius of $0.6 \mu \mathrm{m}$ was used under similar loading and unloading conditions to explore the influence of the tip geometry on the mode of deformation under the indenter. To obtain statistics on pop-out and/or elbow events, as well as the formation of high-pressure phases, 25 indents were performed at each temperature. In order to minimize the effects of thermal drift, the sample and the stage were held at the testing temperature for $1 \mathrm{~h}$ before performing the first indent with an additional $1 \mathrm{~h}$ hold between every two indents. The thermal drift was recorded in terms of drift (rate of change) in penetration depth as $0.019 \mathrm{~nm} / \mathrm{s}$ at RT and $0.055 \mathrm{~nm} / \mathrm{s}$ at $200{ }^{\circ} \mathrm{C}$ during slow unloading. The array of indentations was performed in "piezoautomation" mode, such that the tip always remained in contact with the surface, even while moving from one place on the sample to another. This assisted in maintaining a constant thermal drift. The temperature accuracy was measured with the aid of two thermocouples, one placed under the heating plate and the other on the sample. A temperature gradient of $20^{\circ} \mathrm{C}$ was consistently observed between the heating plate and the sample. Therefore, the temperature was always set $20^{\circ} \mathrm{C}$ higher to achieve the required temperature on the sample surface.

\section{B. Raman microscopy}

The presence of crystalline end phases was determined using a Renishaw 2000 Raman microscope. A $632.8 \mathrm{~nm}$ HeNe laser was employed for exciting the material within the indent through an $\times 80$ objective. The radius of the laser spot on the specimen surface was $\sim 2 \mu \mathrm{m}$ with a power of $\sim 6 \mathrm{~mW}$. As the indents are $\sim 2 \mu \mathrm{m}$ in diameter, the Raman spectra always contain information from both the surrounding matrix of dc-Si and the deformed material in the residual indent impression. It is important to note that while nanoindentation was performed at high temperatures, the residual indent impressions were measured at ambient temperature. Therefore, the Raman spectra show only the remnant phases.

\section{Transmission electron microscopy (TEM)}

XTEM samples of selected residual indents were prepared using an FEI Nova NanoLab 200 dual-beam focused ion beam (FIB) with the ex-situ lift-out technique. ${ }^{41} \mathrm{~A}$ 
Philips CM 300 instrument operating at an accelerating voltage of $300 \mathrm{kV}$ was used for imaging. Selected area diffraction (SAD) was performed directly beneath the residual indent impression.

\section{In-situ high temperature electrical measurement}

In order to detect the formation of the metallic phase during indentation loading at high temperature, in-situ electrical measurements have also been performed. Figure 1 shows a schematic of the experimental setup used for this measurement. The electrical characterization ( $I-V$ curve) at ambient temperature confirmed that a Schottky contact was formed at the Ti-to-epilayer interface. A Schottky contact forms as a result of the lightly doped epilayer that produces a significant depletion layer thickness under the contact and hence acts as a barrier to current flow when a reverse bias is applied. $^{42}$ The area of the Schottky contact was $\sim 1 \mathrm{~cm}^{2}$. The area of contact between the Berkovich indenter and the sample was in the order of $\sim 1 \mu \mathrm{m}^{2}$ at a $P_{\text {max }}$ of $10 \mathrm{mN}$. For this reason, as there were several orders of magnitude difference in the indenter contact area and the Schottky contact, this measurement is highly sensitive to changes in the electronic properties of the region directly under the indenter. Such changes in the electrical data occur due to the transformation of a small region under the indenter from a Schottky to an Ohmic contact (i.e., a dc-Si to $\beta$-Sn transformation) during loading. The Ohmic behaviour is a direct result of the formation of the metallic $\beta$-Sn phase in contact with $\mathrm{Ti}$ and also underlying dc-Si, where the electrical barrier height is low. ${ }^{42}$ A Keithley (Model: 2602) source meter was used for applying a voltage and measuring current flow during indentation.

Before presenting the results of this study, it is worth noting that as the maximum temperature is $200{ }^{\circ} \mathrm{C}$, we assume any increased formation of oxide on the surface is negligible, since $\mathrm{Si}$ is known to only react significantly with oxygen beyond $400^{\circ} \mathrm{C}$. ${ }^{43}$

\section{RESULTS}

\section{A. Nanoindentation}

Figures 2(a) and 2(b) show applied load versus tip displacement depth $(P-h)$ curves obtained from dc-Si when

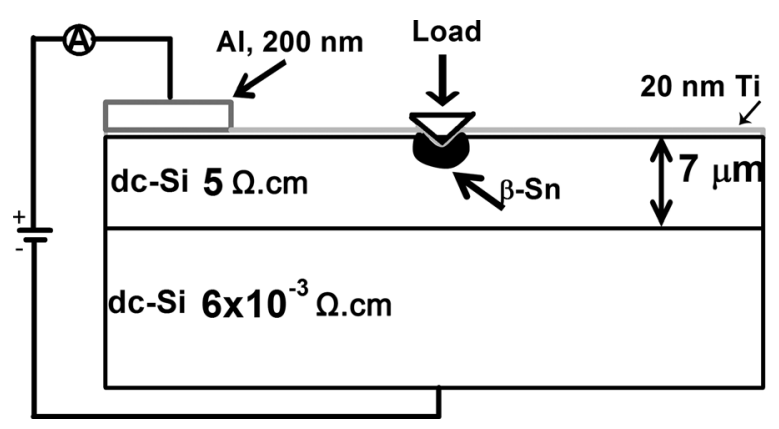

FIG. 1. Schematic of the device used for the in-situ high-temperature electrical measurements. The Si structure consists of a $\sim 7 \mu \mathrm{m}$ epilayer of high resistance $\mathrm{Si}(5 \Omega \mathrm{cm})$ grown on bulk $\mathrm{Si}$ with a very low resistance $(6 \times$ $10^{-3} \Omega \mathrm{cm}$ ). Indents were performed on the samples through a thin $20 \mathrm{~nm} \mathrm{Ti}$ layer for the electrical measurements. A $200 \mathrm{~nm}$ Al layer was evaporated on Ti for the electrical contacts.
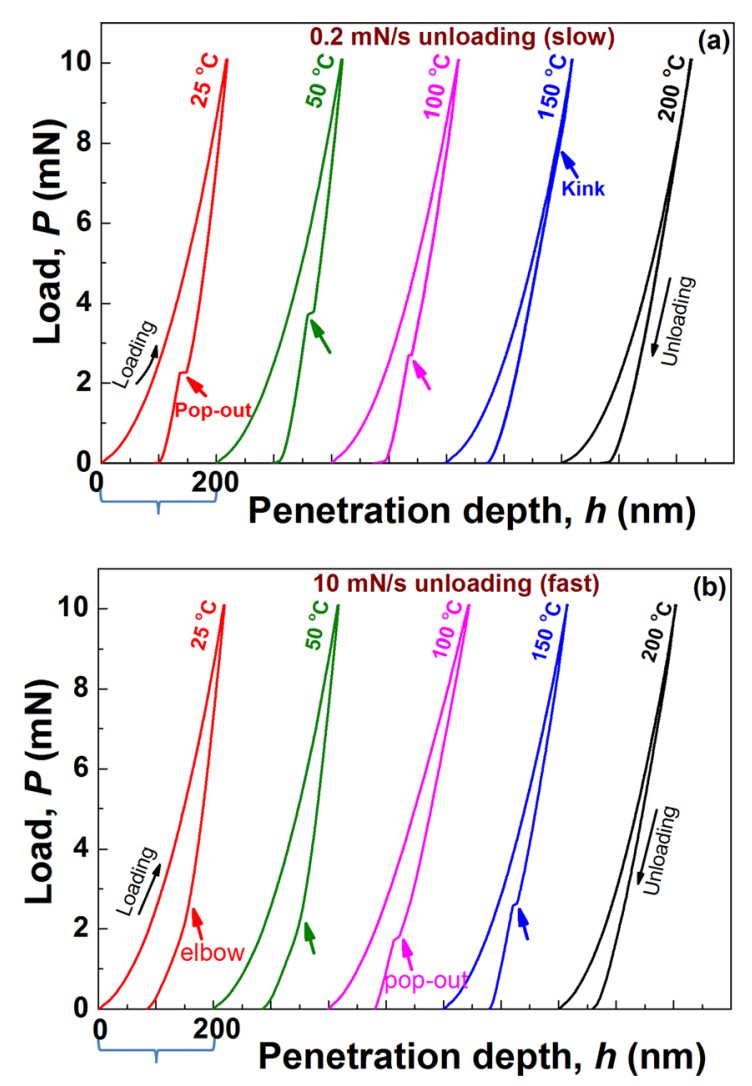

FIG. 2. P-h curves obtained from Berkovich indentation of dc-Si at various temperatures using (a) $0.2 \mathrm{mN} / \mathrm{s}$ and (b) $10 \mathrm{mN} / \mathrm{s}$ unloading rates. The loading rate $(1 \mathrm{mN} / \mathrm{s})$ and hold period $(5 \mathrm{~s})$ are the same for all experiments. The displacements are shifted to greater depths for clarity.

loaded to $10 \mathrm{mN}$ with a Berkovich indenter at various temperatures starting from 25 to $200^{\circ} \mathrm{C}$ and employing the "slow" and "fast" unloading rates. Interestingly, a maximum penetration depth $\left(h_{\max }\right)$ of $220 \pm 5 \mathrm{~nm}$ at $P=10 \mathrm{mN}$ was observed irrespective of the test temperature. While the loading section of all the $P$ - $h$ curves is featureless, the unloading portions exhibit some discontinuous events up to $150{ }^{\circ} \mathrm{C}$, at both "fast" and "slow" unloading rates. During $0.2 \mathrm{mN} / \mathrm{s}$ unloading, such pop-out events were observed consistently up to $75^{\circ} \mathrm{C}$ and with a reduced probability at $100^{\circ} \mathrm{C}$. Although the unload curve at $150{ }^{\circ} \mathrm{C}$ may appear featureless, on close analysis (by taking the derivative), a kink-like popout event can be seen [see Figure S1 in the supplemental material ${ }^{44}$ for the reproducibility of kink-like pop-outs].

However, in contrast, $P$ - $h$ curves recorded at fast unloading exhibit clear pop-out events at $100^{\circ} \mathrm{C}$ and $150^{\circ} \mathrm{C}$ and elbows at $25^{\circ} \mathrm{C}$ and $50^{\circ} \mathrm{C}$, as shown in Fig. 2(b). While elbows are thought to be indicative of the gradual formation of $P I$ a-Si from $\beta$-Sn under the indenter, ${ }^{20,45}$ pop-outs indicate a sudden volume change associated with the newly formed crystalline $\mathrm{r} 8 / \mathrm{bc} 8$ phases. ${ }^{45}$ At $200^{\circ} \mathrm{C}, P$ - $h$ curves show neither pop-outs nor elbows irrespective of unloading rates used, suggesting deformation only via plastic flow. Although the $h_{\text {max }}$ is similar at all temperatures, significant variation is noted in the final depth of penetration on full unloading $\left(\mathrm{h}_{f}\right)$ depending on the unloading rate. In the presence of a pop-out (i.e., $0.2 \mathrm{mN} / \mathrm{s}$ unloading case), the average $\mathrm{h}_{f}$ was recorded as $\sim 100 \mathrm{~nm}$, but as only $\sim 82 \mathrm{~nm}$ in the case of elbows. While 
the higher $\mathrm{h}_{f}$ in the pop-out case is due to the formation of $\mathrm{r} 8$ / bc 8 , which are $\sim 10 \%$ (Ref. 46) less dense than the $\beta$-Sn phase, the lower $\mathrm{h}_{f}$ is attributed to the gradual formation of $P I$ amorphous $\mathrm{Si}$, which is $>20 \%$ less dense than the $\beta$-Sn phase. ${ }^{27}$ This further suggests that up to $150{ }^{\circ} \mathrm{C}$, the $\mathrm{d} c$-Si has phase transformed. The dominant mode of deformation, the types of end phases, and the volume of the transformed zone up to this temperature will be discussed in Section IV with the aid of the ex-situ characterization data.

However, since $\mathrm{h}_{f}$ at $200{ }^{\circ} \mathrm{C}$ (where there are no pop-outs, elbows and kinks in the unloading curve) is significantly smaller $(\sim 60 \mathrm{~nm})$ than at lower temperatures, a different mode of deformation, other than phase transformation, can be assumed. Furthermore, it is interesting to note that the pop-out magnitude, $h_{\text {pop-out }}$ which was $10 \pm 1 \mathrm{~nm}$ at $25^{\circ} \mathrm{C}$ was reduced to $7 \pm 1 \mathrm{~nm}$ at $50^{\circ} \mathrm{C}$ and further decreased to $4 \pm 1 \mathrm{~nm}$ at $100^{\circ} \mathrm{C}$. Although there was no correlation made previously, it appears that there may be a correlation between the pop-out width and the transformed volume. This issue will be further discussed in Section IV.

\section{B. Raman microscopy}

Figure 3 shows Raman spectra obtained from the residual indent impressions of the indents made at various temperatures. Along with the characteristic peaks of dc-Si (at $300 \mathrm{~cm}^{-1}$ and $521 \mathrm{~cm}^{-1}$ ), extra peaks at 350, 397, and
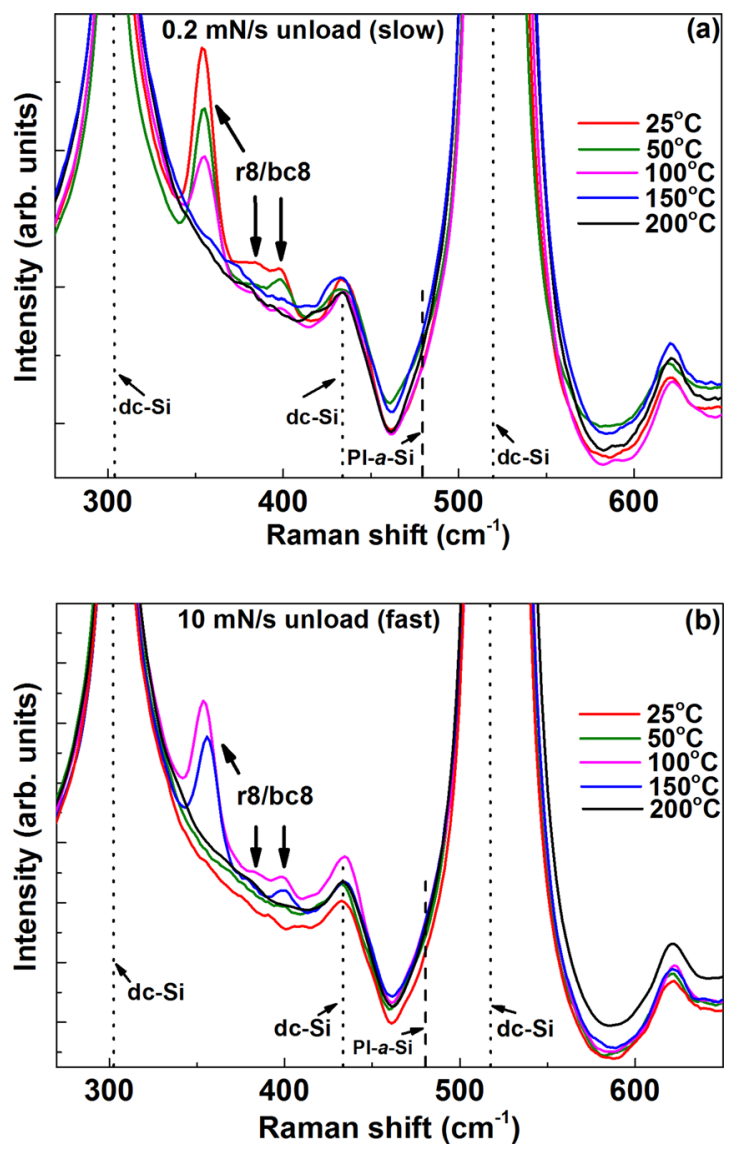

FIG. 3. Raman spectra obtained from Berkovich indents on dc-Si at various temperatures using (a) slow and (b) fast unloading conditions. The dashed line at $480 \mathrm{~cm}^{-1}$ is given to show the characteristic TO peak of PI a-Si. ${ }^{27}$
$384 \mathrm{~cm}^{-1}$ (attributed to $\mathrm{r} 8$ and bc8 $\mathrm{Si}$ phases) ${ }^{17}$ are clearly observed up to $100{ }^{\circ} \mathrm{C}$ during slow unloading but during fast unloading they instead occur only at $100^{\circ} \mathrm{C}$ and $150^{\circ} \mathrm{C}$. This latter result is consistent with unloading curves where an elbow below $100^{\circ} \mathrm{C}$ suggests the formation of $\mathrm{PI}$ a-Si. Thus, phase transformations appear to be evident up to $150{ }^{\circ} \mathrm{C}$. The characteristic broad TO peak at $480 \mathrm{~cm}^{-1}$ (not seen in the present study) can indicate the presence of $P I$ a-Si (formed from $\beta$-Sn phase) within the residual indent. Although fast unloading conditions favour formation of an amorphous volume, no significant broad peak was observed in the Raman spectra. This is most likely due to the weak a-Si peak compared to the scattering associated with the strong surrounding dc-Si signal. This will be further discussed later with the aid of XTEM and electrical results.

At $200{ }^{\circ} \mathrm{C}$, no bc $8 / \mathrm{r} 8$ peaks are observed irrespective of the unloading rates used in this study. This fits extremely well with the absence of pop-out/elbow/kink events in the $P$ - $h$ curves at $200{ }^{\circ} \mathrm{C}$ (see Fig. 2). This again signifies that the dominant deformation mode is likely to be plastic flow rather than via phase transformation.

\section{Transmission electron microscopy}

Figure 4 shows the XTEM bright and dark-field images of residual Berkovich indents of $\mathrm{dc}-\mathrm{Si}$ at various temperatures during slow unloading along with SAD patterns from the regions directly beneath the residual indents, as shown with a circle on Fig. 4(a). The SADPs were taken with a selected area aperture of $\sim 500 \mathrm{~nm}$ diameter which is larger than the phase transformed volumes. Hence, the SADPs contain the responses from both the dc-Si and phase transformed zones. Indents made at $25^{\circ} \mathrm{C}$ and $100{ }^{\circ} \mathrm{C}$ [Figs. 4(a) and 4(b)] show the presence of phase transformed zones within the deformed volume. Apart from dc-Si reflections, there are several extra diffraction spots which are known to be characteristic reflections from polycrystalline $\mathrm{r} 8$ and/or bc8, as shown in Fig. 4(b). The spacing of the diffraction spots observed in this study is consistent with the results from previous work. ${ }^{47,48}$ It is worth noting the increase in the defect density in dc-Si under the transformed zone at $100^{\circ} \mathrm{C}$ compared with $25^{\circ} \mathrm{C}$.

Figure 4(c) shows the XTEM dark field image of the residual indent made at $150{ }^{\circ} \mathrm{C}$ under slow unloading conditions. It is evident from the image that only a very small phase transformed volume can be noticed. The corresponding SAD pattern shows the presence of amorphous material along with characteristic dc-Si reflection spots and very weak r8 and bc8 spots. Moreover, a clear presence of twins running along the $\{111\}$ planes can be observed. Furthermore, streaking between the diffraction spots also suggests that the material may have preferentially deformed via a twinning mechanism. ${ }^{49}$ Similar to the slow unloading conditions at $150{ }^{\circ} \mathrm{C}$, the XTEM images of fast unloading at $150^{\circ} \mathrm{C}$ show traces of $\mathrm{r} 8$ and $\mathrm{bc} 8$ phases and twins running along $\{111\}$ planes [see Figure S2] ${ }^{44}$ At $200^{\circ} \mathrm{C}$, no significant phase transformation activity but strong twinning along $\{111\}$ planes is evidenced under the indenter, as shown in Fig. 4(d). The corresponding SAD pattern with diffraction 

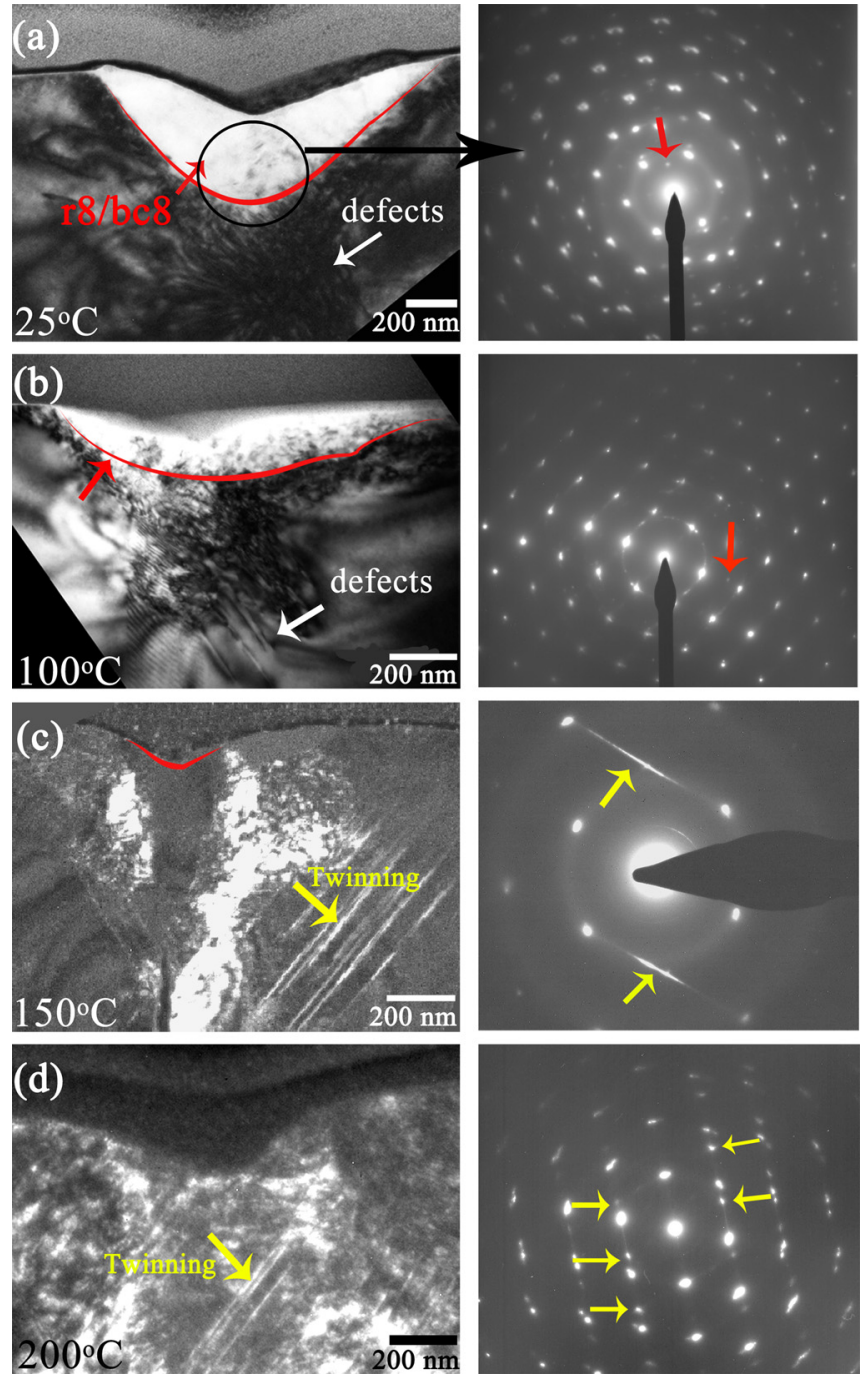

FIG. 4. (a) and (b) Bright-field and (c) and (d) dark-field XTEM images along with the SAD patterns of Berkovich indents indented to a maximum load of $10 \mathrm{mN}$ with an unloading rate of $0.2 \mathrm{mN} / \mathrm{s}$. SAD patterns were captured directly beneath the residual Berkovich impression to identify the crystal structure of the phase transformed volumes. Since the aperture size used to obtain the SADPs is larger than the phase transformed volume, the SADPs contain the responses from both the dc-Si and phase transformed zones. Diffraction spots from bc $8 / \mathrm{r} 8$ are represented with red arrows. The yellow arrows in (c) and (d) represent twinning and in their corresponding SADPs represent streaking and spot splitting due to twinning, respectively. For clarity, the red lines in the XTEM images illustrate the boundary between phase transformed and untransformed volumes under the indenter.

spot streaking and splitting confirms the presence of twinning. To further understand the phase transformation process during indentation loading, in-situ electrical measurements have been carried out, as shown below.

\section{In-situ high-temperature electrical measurement}

Figure 5 shows both the mechanical and corresponding electrical behaviours of dc-Si during Berkovich indentation during slow unloading at a constant voltage of $1 \mathrm{~V}$ (reverse bias). The insets of Fig. 5 show the $P$ - $h$ curves of the Ti $(20 \mathrm{~nm}) / \mathrm{dc}-\mathrm{Si}$ structure. It is evident from the figure that the loading portions are smooth, but pop-outs in the unloading curves (up to $100{ }^{\circ} \mathrm{C}$ ) indicate the occurrence of an initial phase transformation from dc-Si to $\beta$-Sn during loading and further transformation to $\mathrm{r} 8 / \mathrm{bc} 8$ during unloading, as discussed above. The deformation pathways suggested by the mechanical behaviour are in agreement with the in-situ electrical measurements. Prior to loading, at $25^{\circ} \mathrm{C}$, the device's reverse "leakage" current (i.e., the current that flows through the device before loading) without any previous indent is in the order of a few $\mathrm{nA}$, indicating that a good Schottky contact has been established between the $\mathrm{Ti}$ and the underlying Si. During loading, the current value remains in the $\mathrm{nA}$ range up to a penetration depth of $40 \pm 5 \mathrm{~nm}$, where a gradual increase in current is evident with increasing penetration depth (up to $250 \mathrm{~nm}$ ), as shown in Fig. 5. The peak current at the maximum penetration depth is $14 \pm 1 \mu \mathrm{A}$. This gradual increase in the current can be attributed to an increasing volume of the metallic $\beta$-Sn phase under the indenter that changes the properties of the contact from Schottky to Ohmic-like. However, during unloading, the current falls rapidly which we discuss later in terms of further phase transformation processes occurring on unloading.

It should be noted that the device reverse leakage current prior to indentation loading rises with increasing temperature, for example, to $\sim 8 \mu \mathrm{A}$ at $100^{\circ} \mathrm{C}$. However, this rise in the device leakage current does not affect the transformation current measurement. Similar to the behaviour at $25^{\circ} \mathrm{C}$, the current at $100^{\circ} \mathrm{C}$ was constant up to a penetration depth of $40 \pm 5 \mathrm{~nm}$, and a gradual increase is evident with increasing penetration depth. In this case, the measured transformation current increase is $8.3 \mu \mathrm{A}$. Upon removal of load, the measured current decreases to the starting value. With a further increase in temperature to $125^{\circ} \mathrm{C}$, no significant hysteresis is seen and the increase in current measured during loading was relatively small (i.e., $\sim 2.2 \mu \mathrm{A}$ ). At $150{ }^{\circ} \mathrm{C}$ and beyond, there is no additional current flow observed during indentation loading and a constant value is measured. Note, however, that the residual device leakage current is high $(\sim 22 \mu \mathrm{A})$ in the $200^{\circ} \mathrm{C}$ case and this could mask any small increase in current on loading. The $I-h$ curve at $200{ }^{\circ} \mathrm{C}$ (slow unloading) is presented in Figure S3 for completeness. $^{44}$ It should be further noted that it neither shows any measurable current increase during indentation.

\section{DISCUSSION}

Although the previous micro-indentation studies of dcSi suggest that phase transformation is the dominant mode of deformation up to $350{ }^{\circ} \mathrm{C},{ }^{32}$ our nanoscale results clearly show that defect propagation mechanisms dominate deformation at temperatures as low as $200^{\circ} \mathrm{C}$. Figure 6 summarizes the deformation processes in $\mathrm{Si}$ under a nanoscale Berkovich indenter obtained in the current study.

As represented in Fig. 6 , at $25^{\circ} \mathrm{C}$, while the dominant mode of deformation under the indenter is pressure-induced metallization during loading, limited crystalline defects (under the transformed volume) are also evident. With increasing temperature, while the probability of phase transformation and formation of the metallic phase decrease, deformation via defect propagation (such as twinning) increases. At intermediate temperatures between about $60^{\circ} \mathrm{C}$ and $150^{\circ} \mathrm{C}$, both deformation mechanisms (i.e., phase 


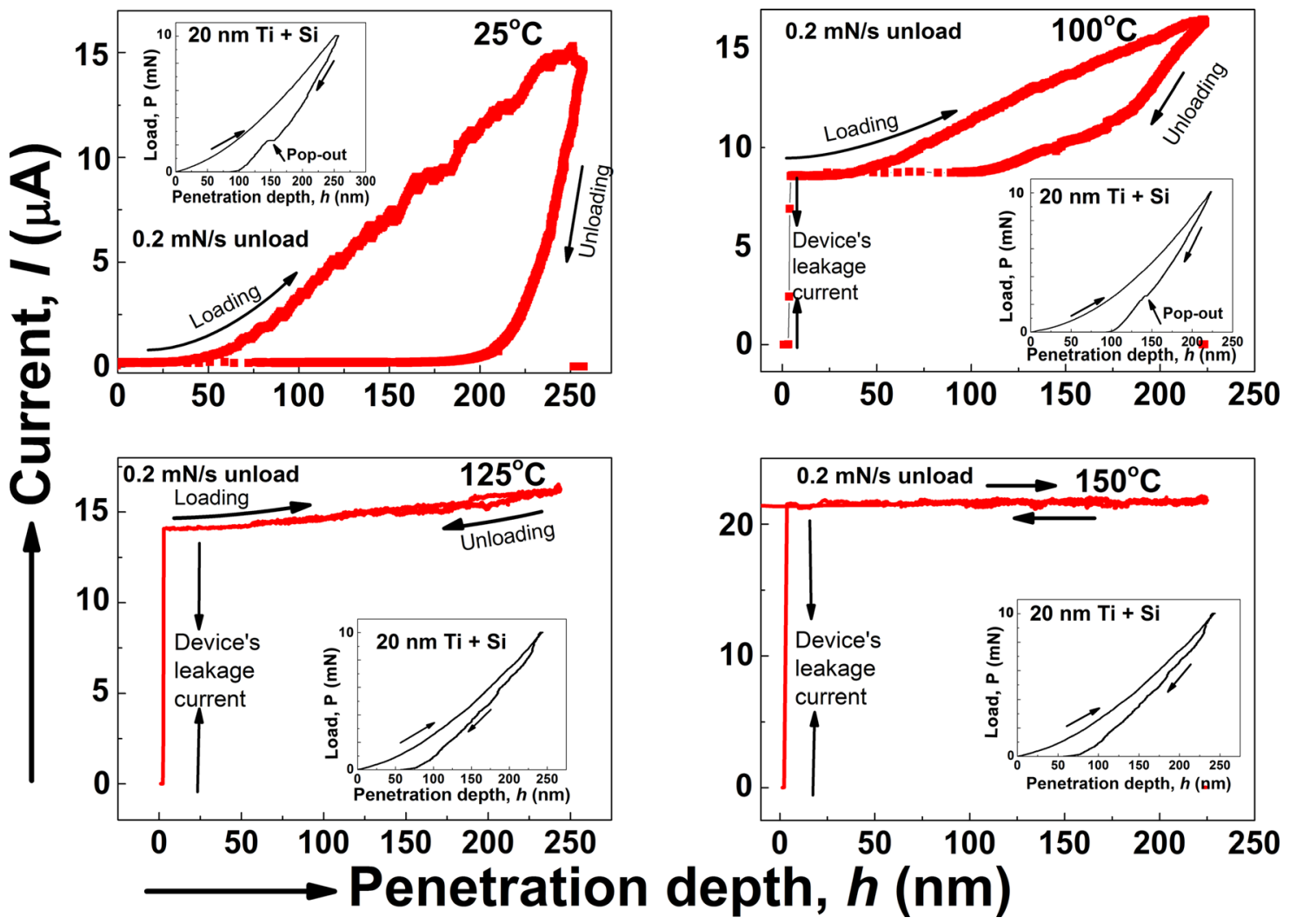

FIG. 5. Current-depth curves from the device structure at a load of $10 \mathrm{mN}$ (under slow unloading conditions) at various temperatures up to $150^{\circ} \mathrm{C}$. The insets show the corresponding P-h curves obtained during indentation.

transformation and defect propagation) are active and contribute significantly to the permanent deformation of $\mathrm{Si}$. At $200^{\circ} \mathrm{C}$, our data indicate that $\mathrm{Si}$ deforms entirely via defect propagation. This indeed suggests that the dominant deformation mechanism under the indenter can to some extent be controlled by carefully choosing the temperature regime and contact loading conditions. We now discuss some of the mechanisms that underpin the above results in detail.

It is evident that phase transformation is clearly a major mode of deformation in $\mathrm{Si}$ under the nanoindenter up to $125^{\circ} \mathrm{C}$. The electrical measurements (Fig. 5) clearly

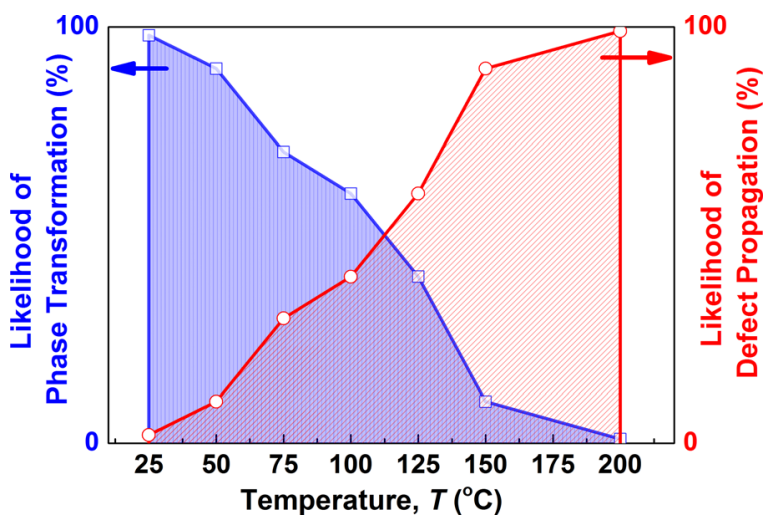

FIG. 6. Schematic of the temperature dependence of the deformation mechanisms of dc-Si under a nanoscale Berkovich indenter, presuming that the probabilities of the two deformation processes sum up to $100 \%$. The lines connecting data points are to guide the eye and do not represent any fit. The estimates of the transformed volume (from XTEM) for elevated temperatures with respect to RT are used to plot the likelihood of phase transformation. demonstrate that the transformation to a metallic phase occurs up to $125^{\circ} \mathrm{C}$ during loading. Additionally, it is important to note that up to $75^{\circ} \mathrm{C}$ [see Figure S4], ${ }^{44}$ the peak current is roughly constant $(\sim 14 \mu \mathrm{A})$ indicating that the volume of the transformed zone is likewise, approximately constant. However, above $75^{\circ} \mathrm{C}$, the peak current decreases. At $100^{\circ} \mathrm{C}$, the peak current value reduces to $\sim 8.3 \mu \mathrm{A}$ (i.e., $\sim 40 \%$ lower) indicating a corresponding decrease in the metallic volume under the indenter. This means that other modes of deformation may be occurring. Figure 4(b) shows a smaller transformed volume than lower temperatures and planar defects running along $\{111\}$ planes under the indenter. The propagation of such defects would clearly contribute to a component of plastic deformation in this case. With further increase in the temperature to $125^{\circ} \mathrm{C}$, the peak current due to the metallic transformation significantly reduces to $\sim 2 \mu \mathrm{A}$. If the current value reflects the magnitude (roughly linearly) of the volume of $\beta$-Sn, this indicates only $\sim 15 \%$ of the volume at $125^{\circ} \mathrm{C}$ has been transformed to the metallic phase.

During unloading, as expected, the slow unloading rate has resulted in $\mathrm{r} 8$ and bc8 end phases up to $125^{\circ} \mathrm{C}$ (as revealed by the Raman and SAD patterns). In contrast to a previous report, ${ }^{36}$ no additional spots that could be attributed to a tetragonal phase were observed in this study at $100^{\circ} \mathrm{C}$. However, as mentioned earlier, a continuous decrease in the pop-out magnitude (Fig. 2), Raman peak intensity for the r8/ bc8 phases (Fig. 3), and metallic transformation currents with increasing temperature (Fig. 5) indicates that the volume of the transformed zone decreases with increasing 
temperature. This is confirmed by the TEM results, as shown in Fig. 4.

Here, it is now worth discussing the reduced probability of pop-outs during slow unloading compared to fast unloading at $100^{\circ} \mathrm{C}$ and $125^{\circ} \mathrm{C}$. This is somewhat surprising as slow unloading conditions are known to induce pop-outs (and $\mathrm{r} 8 / \mathrm{bc} 8$ phases) at room temperature, while fast unloading rates promote elbows (and an a-Si end phase), as discussed above. Similar findings have been reported by Ruffell et al. ${ }^{37}$ that showed a decreased probability of pop-out events with increasing temperature under slow unloading beyond $75^{\circ} \mathrm{C}$ and a complete absence of them at $\geq 125^{\circ} \mathrm{C}$. In contrast, fast unloading conditions favored pop-outs at both $100^{\circ} \mathrm{C}$ and $125^{\circ} \mathrm{C} .{ }^{37}$ Our present study reveals that although there are no major pop-outs in the unloading curves at $100^{\circ} \mathrm{C}$ and $125^{\circ} \mathrm{C}$ during slow unloading, XTEM images and SAD patterns show that there are small regions of $\mathrm{r} 8 / \mathrm{bc} 8$ phases within the residual indents, as shown in Fig. 4. This behaviour can be further understood with the aid of electrical measurements as shown in Fig. 7. At $100^{\circ} \mathrm{C}$, the current increase during loading and the peak currents at the $P_{\max }$ are the same for both fast and slow unloading rates, indicating a similar volume of metallic phase under the indenter at maximum load in both the cases. This is not surprising since the loading conditions were the same in both cases. However, the current decrease during unloading is completely different, indicating a difference in the metallic to $\mathrm{r} 8 / \mathrm{bc} 8$ transformation process. While fast unloading conditions show a rapid current decrease to the starting value, slow unloading conditions show a gradual drop in the measured current.

It is difficult to explain the shape of the $I-h$ curves during unloading in terms of phase transformations. For example, for the fast unloading rate in Fig. 7, the pop-out which signifies a large volume of the $\beta$-Sn phase suddenly transforming to $\mathrm{r} 8 / \mathrm{bc} 8$ phases, occurs at a $h$-value of $\sim 125 \mathrm{~nm}$, whereas the major drop in $I$ occurs much deeper at between $h_{\max }$ and about $\sim 175 \mathrm{~nm}$. This may suggest that the measured $I$ drop is dominated more by interfacial changes. In particular, during unloading, the deeper extremities of the $\beta$-Sn volume will first experience a pressure below the $\sim 11 \mathrm{GPa}$ critical pressure and this is exactly at the (Ohmic-like) interface between $(\beta-\mathrm{Sn})-\mathrm{Si}$ and dc-Si. It may be that the

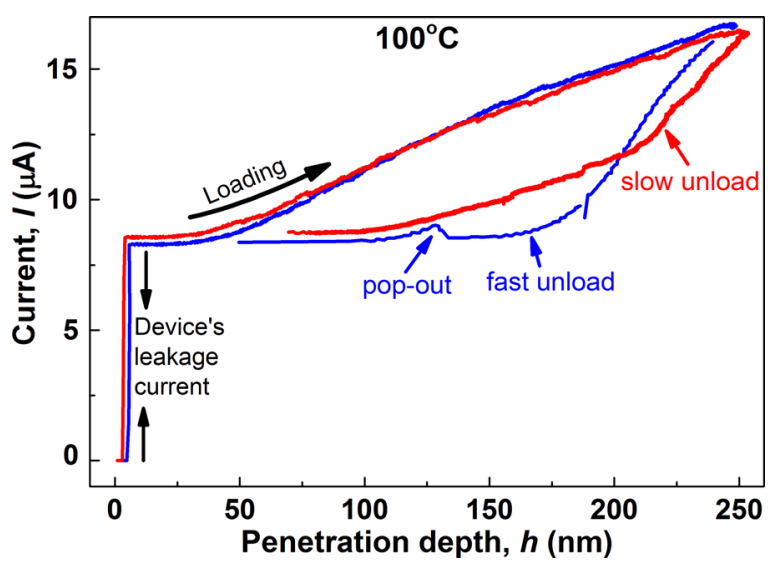

FIG. 7. The $I-h$ curves obtained during indentation with a Berkovich tip at $100^{\circ} \mathrm{C}$ at both fast and slow unloading rates. pressure drop causes interfacial changes and a rapid progression from Ohmic to Schottky behaviour at this interface irrespective of whether there is a well-defined phase change or not. Such behaviour could account for the rapid drop in $I$ for both fast and slow unloading. Indeed, subtle changes in the nature of this interface, such as that resulting from fast and slow unloading, could change the shape of the $I$ vs $h$ curve on unloading. For example, for slow unloading, there is often no pop-out (or only a small magnitude pop-out) as shown in Figs. 2 and 7. Hence, it may be the case that some level of continuous transformation to $\mathrm{r} 8 / \mathrm{bc} 8$ occurs on slow unloading and the resultant interface changes influence the Ohmic/ Schottky behaviour as reflected in a different initial slope of the $I$ vs $h$ unloading curve.

While the pop-outs (and kink like pop-outs) in the $P$ - $h$ curves, Raman peaks, and the XTEM images confirm the formation of some small regions of $\mathrm{r} 8 / \mathrm{bc} 8$ phases particularly during fast unloading at $150^{\circ} \mathrm{C}$, in-situ electrical measurements show a negligible increase in the metallic transformation current during loading. This is most likely a result of the fact that the device leakage current is high $(\sim 22 \mu \mathrm{A})$ and this could mask any small increase in current on loading, noting that the transformed volume is small.

Therefore, it is further interesting to consider the XTEM results for this regime. The dark-field images from the slow unloading indents [Figs. 4(c) and 4(d)] show the clear presence of convergent twins running along $\{111\}$ planes beyond $150{ }^{\circ} \mathrm{C}$. The SAD pattern that was captured from the deformed area exhibits strong dc-Si spots along with spot splitting, indicative of twinning as indicated in Figs. 4(c) and 4(d). In fact, the twinning mechanism in dc-Si is known at temperatures beyond $350^{\circ} \mathrm{C} .{ }^{24,29,49,50}$ For the diamond structure, the $\{111\}$ planes are natural twinning planes. Such twinning under a spherical indenter has been reported at RT for Ge (Ref. 51) along the $\{111\}$ planes at an indentation force of $50 \mathrm{mN}$ at room temperature but has not been observed previously for $\mathrm{Si}$ at lower temperatures (i.e., below $350^{\circ} \mathrm{C}$ ) despite the fact that clear "defects" on the $\{111\}$ planes have previously been observed in Si even under RT indentation. ${ }^{52}$ Along with the twins, the SAD pattern in Fig. 4(c) shows weak amorphous rings and faint spots from $\mathrm{r} 8 / \mathrm{bc} 8$ phases. This shows that the dominant mode of deformation under the indenter at elevated temperature is complex. Aside from the twinning mentioned above, there may have been small zones that have undergone pressure-induced phase transformations (resulting in the $\mathrm{r} 8 / \mathrm{bc} 8$ ). The weak amorphous rings in the SAD patterns are presumed caused by ion beam damage during the lamella preparation in the FIB.

In increasing temperature to $100^{\circ} \mathrm{C}$, it is evident from the Fig. 4 that the phase transformed volume (depth of zone) decreased by around a factor of two from the RT case, with a significant increase in the density and intensity of defects running under the transformed zone. This clearly indicates that at least half of the plastic energy has been utilized in activating the defects under the transformed zone. The further increase in temperature to $150{ }^{\circ} \mathrm{C}$ causes enhanced defect propagation and this mode of plastic deformation now dominates phase transformation where only small regions of the $r 8 / b c 8$ phases exist. The schematic diagram in Fig. 6 
depicts the competition between these two deformation mechanisms where the observed volume of the transformed zone relative to the RT case is used to roughly estimate the degree of phase transformation.

The clear observation of significant twinning at $150^{\circ} \mathrm{C}$ and the appearance of $\{111\}$-line defects under the indenter below $150{ }^{\circ} \mathrm{C}$ warrant some further comment. In Fig. 4(b) for indentation at $100^{\circ} \mathrm{C}$, there are clearly "defects" running along $\{111\}$ Si planes but their density is considerably lower than that for $150{ }^{\circ} \mathrm{C}$ [Fig. 4(c)]. In addition, there is significant crystalline disorder at depths between the $\{111\}$-line defects and the transformed zone in Fig. 4(b) that is difficult to classify in terms of specific defects. At $25^{\circ} \mathrm{C}$, where phase transformation is the dominant deformation mechanism, there is some observable disorder but it is not possible here to identify clear $\{111\}$-line defects or twins. However, in indentation studies at $25^{\circ} \mathrm{C}$ using spherical indenters up to $\sim 4 \mu \mathrm{m}$ diameter, there is clear evidence for defects running along $\{111\}$ planes $^{52}$ which would appear to be $\{111\}$-line defects and may be the embryos of twins observed at highest temperatures, although not specifically identified as such in that earlier paper. ${ }^{52}$ Hence, we propose that even at RT, small $\{111\}$-line defects (and less well-defined "defects") may be present following indentation and, with increasing temperature, $\{111\}$ twins occur in higher concentrations, with the observed twins extending to increasingly larger distances below the residual indent. Such defect propagations provide an increasing component of plastic deformation as temperature increases.

However, at $200^{\circ} \mathrm{C}$, as XTEM images show in Fig. 4(d), twinning induced deformation is the dominant mode with no evidence for phase transformation observed in the present study. Indeed, the absence of pop-out events in the $P$ - $h$ curves and absence of $\mathrm{r} 8 / \mathrm{bc} 8$ peaks in the Raman spectra corroborate well with these results. It is interesting to note here that the mechanism of deformation at $200{ }^{\circ} \mathrm{C}$ under the nanoindenter is independent of the loading rates and tip geometry used in this study [see Figs. S5 and S6]. ${ }^{44}$ Hence, under the conditions used in the present study, as we depict in Fig. 6, defect propagation is essentially the sole deformation mechanism at $200^{\circ} \mathrm{C}$.

We indicated in the introduction that there was considerable discrepancy in the previous literature as to the dominant plastic deformation mode of $\mathrm{Si}$ at elevated temperature both for nanoindentation and microindentation studies. Our current study indicates that the two deformation modes of phase transformation and defect propagation are not mutually exclusive with contributions from both occurring over the whole temperature range but to different degrees. We propose that several parameters can determine which deformation mode dominates (or is observed), including temperature but also indenter shape, size, maximum load, and loading rate. In most of the previous elevated temperature indentation studies, evidence for phase transformation (exclusively from Raman experiments $)^{32}$ has been obtained at temperatures well in excess $200^{\circ} \mathrm{C}$. However, there was no attempt in such studies to determine a dominant deformation mode and it is clear from previous TEM studies that a very dense level of crystalline disorder exists in this temperature range.
We suggest that the indentation conditions, including an excessively high load in most cases, may have contributed to the observation of phase transformations at temperatures above $200^{\circ} \mathrm{C}$. For example, it may well be that defect propagation dominated at lower loads in such cases but excessively dense and interacting defect concentrations inhibited further defect propagation at higher loads, thus permitting the pressure under the indenter to exceed the phase transformation pressure as load increased. In other cases, it may well have been an extremely high loading rate that favoured phase transformations since defect propagation may not have occurred fast enough to keep the pressure under the indenter tip below the critical $\sim 11-12 \mathrm{GPa}$. In our case, although we tried high loading rates $(10 \mathrm{mN}$ force in $0.1 \mathrm{~s})$ at $200^{\circ} \mathrm{C}$, we could not induce phase transformation up to a maximum load of $10 \mathrm{mN}$. We suggest that up to such low maximum loads and nanosize indenter tips, we may need exceeding fast loading rates to inhibit defect propagation.

Our study clearly indicates that the mode of deformation can be easily tailored in materials by strategically choosing the indentation conditions that favour particular modes of deformation under the nanoindenter. In other words, phase transformations may indeed be possible even at $200^{\circ} \mathrm{C}$ and above at the nanoscale if the loading rates and maximum load are extremely high, and also if the size of the indenter is large, similar to the loading and indenter geometry conditions used in the early microindentation studies. However, under such large indenters, it will be difficult to assess the dominant mode of deformation since the defect density will be extremely high in such cases. Finally, it is further interesting that we observe only a small change in the maximum penetration depth at $10 \mathrm{mN}$ load in the present study despite there being different mechanisms of deformation that exists under the indenter over the entire temperature range. This suggests that under the conditions of this study, both plastic deformation mechanisms are activated at around the same critical pressure. However, to adequately address the issue of the temperature dependence of the mechanical properties, such as hardness and modulus of $\mathrm{Si}$ under regimes where one or the other deformation mode is dominant at the nanoscale, further more detailed studies are necessary.

\section{CONCLUSIONS}

In-situ high-temperature indentation has been performed on dc-Si in order to investigate the temperature dependence of indentation-induced phase transformation behavior at the nanoscale. These experiments provide new insights into the temperature dependence of the transformation behavior of dc-Si during nanoindentation. Our study shows that dc-Si can be phase transformed to moderate volumes of the metallic $\beta$-Sn phase during loading below $150{ }^{\circ} \mathrm{C}$ under nanoindentation conditions, but beyond that temperature twinning-induced plasticity is the dominant mode of deformation (under the conditions used in this study). The absence of a rise in the transformation current $\geq 150^{\circ} \mathrm{C}$ confirms our argument that the semiconductor to the metallic phase transformation is not the dominant mechanism at temperatures above $150^{\circ} \mathrm{C}$ at the nanoscale. This study evidently shows 
that the nanoscale deformation mechanism in $\mathrm{Si}$ beyond $150{ }^{\circ} \mathrm{C}$ differs from that previously proposed for micro/ macro experiments where phase transformations have been observed even up to $450{ }^{\circ} \mathrm{C}$. This has been attributed to the difference in the loading conditions, such as extremely high loads and high loading rates, as well as large indenter size. Indeed, we have shown that over the entire temperature range of our study, both phase transformation and defect propagation occur but to different degrees depending on indentation temperature. In previous studies that have observed phase transformation above $200{ }^{\circ} \mathrm{C}$, it may well have been that defect propagation was dominant but excessively high loads (and loading rates) caused the pressure under the indenter to exceed the critical phase transformation pressure at high load. This improved understanding of the temperature dependence of deformation and the fact that phase change and defect propagation are not mutually exclusive deformation mechanisms over large temperature ranges, will be important in any development of novel high-temperature applications of $\mathrm{Si}$ and possibly other semiconductors subjected to point loading.

\section{ACKNOWLEDGMENTS}

This work has been supported by the Australian Research Council. The Australian National Fabrication Facility (ANFF), ACT Node is acknowledged for use of their FIB facility and the Australian Microscopy and Microanalysis Research Facility for access to electron microscopy facilities at ANU. J.E.B. gratefully acknowledges the Australian Research Council for a Future Fellowship. B.H. gratefully acknowledges current funding from an Alvin M. Weinberg Fellowship and through the Spallation Neutron Source, sponsored by the U.S. Department of Energy, Office of Basic Energy Sciences.

${ }^{1}$ A. Mujica, A. Rubio, A. Munoz, and R. J. Needs, Rev. Mod. Phys. 75, 863 (2003).

${ }^{2}$ N. Fujisawa, J. S. Williams, and M. V. Swain, J. Mater. Res. 22, 2992 (2007).

${ }^{3}$ B. G. Pfrommer, M. Cote, S. G. Louie, and M. L. Cohen, Phys. Rev. B 56, 6662 (1997).

${ }^{4}$ R. J. Needs and A. Mujica, Phys. Rev. B 51, 9652 (1995).

${ }^{5}$ J. C. Jamieson, Science 139, 762 (1963).

${ }^{6}$ H. Olijnyk, Phys. Rev. Lett. 68, 2232 (1992).

${ }^{7}$ J. Z. Hu, L. D. Merkle, C. S. Menoni, and I. L. Spain, Phys. Rev. B 34, 4679 (1986).

${ }^{8}$ J. Crain, G. J. Ackland, J. R. Maclean, R. O. Piltz, P. D. Hatton, and G. S. Pawley, Phys. Rev. B 50, 13043 (1994).

${ }^{9}$ R. O. Piltz, J. R. Maclean, S. J. Clark, G. J. Ackland, P. D. Hatton, and J. Crain, Phys. Rev. B 52, 4072 (1995).

${ }^{10}$ K. J. Chang and M. L. Cohen, Phys. Rev. B 31, 7819 (1985).

${ }^{11}$ B. D. Malone, J. D. Sau, and M. L. Cohen, Phys. Rev. B 78, 035210 (2008).

${ }^{12}$ S. Ruffell, K. Sears, A. P. Knights, J. E. Bradby, and J. S. Williams, Phys. Rev. B 83, 075316 (2011).

${ }^{13}$ R. Rao, J. E. Bradby, and J. S. Williams, Appl. Phys. Lett. 91, 123113 (2007).

${ }^{14}$ G. M. Pharr, W. C. Oliver, R. F. Cook, P. D. Kirchner, M. C. Kroll, T. R. Dinger, and D. R. Clarke, J. Mater. Res. 7, 961 (1992).
${ }^{15}$ E. R. Wepplmann, J. S. Field, and M. V. Swain, J. Mater. Sci. 30, 2455 (1995).

${ }^{16}$ V. Gridneda, Yu. V. Milman, and V. I. Trefilov, Phys. Status Solidi A 14, 177 (1972).

${ }^{17}$ A. Kailer, K. G. Nickel, and Y. Gogotsi, J. Raman Spectrosc. 30, 939 (1999).

${ }^{18}$ Y. B. Gerbig, C. A. Michaels, A. M. Forster, and R. F. Cook, Phys. Rev. B 85, 104102 (2012).

${ }^{19}$ Y. B. Gerbig, S. J. Stranick, and R. F. Cook, Phys. Rev. B 83, 205209 (2011).

${ }^{20}$ Y. B. Gerbig, S. J. Stranick, and R. F. Cook, J. Mater. Res. 24, 1172 (2009).

${ }^{21}$ J. Watson and G. Castro, "High-temperature electronic pose design and reliability challenges," Analogue Dialogue 46, 1 (2012), available at http://www. analog.com/library/analogdialogue/archives/46-04/high_temp_electronics.html.

${ }^{22}$ J. J. Gilman, Science 261, 1436 (1993).

${ }^{23}$ T. Suzuki and T. Ohmura, Philos. Mag. A 74, 1073 (1996).

${ }^{24}$ V. G. Eremenko and V. I. Nikitenko, Phys. Status Solidi A 14, 317 (1972).

${ }^{25}$ R. M. Wentorf, Jr. and J. S. Kasper, Science 139, 338 (1963).

${ }^{26}$ B. Haberl, M. Guthrie, S. V. Sinogeikin, G. Shen, J. S. Williams, and J. E. Bradby, High Pressure Res. 35, 99 (2015).

${ }^{27}$ B. Haberl, A. C. Y. Liu, J. E. Bradby, S. Ruffell, J. S. Williams, and P. Munroe, Phys. Rev. B 79, 155209 (2009).

${ }^{28}$ G. L. Olson and J. A. Roth, Mater. Sci. Rep. 3, 1 (1988).

${ }^{29}$ P. Pirouz, R. Chaim, U. Dahmen, and K. H. Westmacott, Acta Metall. Mater. 38, 313 (1990).

${ }^{30}$ C. Cayron, M. D. Hertog, L. L. Romain, C. Mouchet, C. Secouard, J. L. Rouviere, E. Rouviere, and J. P. Simonato, J. Appl. Crystallogr. 42, 242 (2009).

${ }^{31}$ M. I. D. Hertog, C. Cayron, P. Gentile, F. Dhalluin, F. Oehler, T. Baron, and J. L. Rouviere, Nanotechnology 23, 025701 (2012).

${ }^{32}$ V. Domnich, Y. Aratyn, W. M. Kriven, and Y. Gogotsi, Rev. Adv. Mater. Sci. 17, 33 (2008), available at http://www.ipme.ru/e-journals/RAMS/ no_11708/gogotsi.pdf.

${ }^{33}$ D. Ge, V. Domnich, and Y. Gogotsi, J. Appl. Phys. 95, 2725 (2004).

${ }^{34}$ J. M. Antunes, A. Cavaleiro, L. F. Menezes, M. I. Simoes, and J. V. Fernandes, Surf. Coat. Technol. 149, 27-35 (2002).

${ }^{35}$ W. C. Oliver and G. M. Pharr, J. Mater. Res. 7, 1564 (1992).

${ }^{36}$ R. K. Singh, P. Munroe, and M. Hoffman, J. Mater. Res. 23, 245 (2008).

${ }^{37}$ S. Ruffell, J. E. Bradby, J. S. Williams, D. M. Paniagua, S. Tadayyon, L. L. Coastworth, and P. R. Norton, Nanotechnology 20, 135603 (2009).

${ }^{38}$ S. K. Bhuyan, J. E. Bradby, S. Ruffell, B. Haberl, C. Saint, and J. S. Williams, MRS Comm. 2, 9 (2012).

${ }^{39}$ V. Bhakhri and R. J. Klassen, J. Mater. Sci. 41, 2259 (2006).

${ }^{40}$ J. C. Trenkle, C. E. Packard, and C. A. Schuh, Rev. Sci. Instrum. 81, 073901 (2010).

${ }^{41}$ R. M. Langford and M. Rogers, Micron 39, 1325 (2008).

${ }^{42}$ J. E. Bradby, J. S. Williams, and M. V. Swain, Phys. Rev. B 67, 085205 (2003).

${ }^{43}$ H. Kakiuchi, H. Ohmi, M. Harada, H. Watanabe, and K. Yasutake, Appl. Phys. Lett. 91, 161908 (2007).

${ }^{44}$ See supplementary material at http://dx.doi.org/10.1063/1.4921534 for further information about the XTEM images of the residual indents at various temperatures and indentation data.

${ }^{45}$ T. Juliano, Y. Gogotsi, and V. Domnich, J. Mater. Res. 18, 1192 (2003).

${ }^{46}$ J. S. Williams, Y. Chen, J. Wong-Leung, A. Kerr, and M. Swain, J. Mater. Res. 14, 2338 (1999).

${ }^{47} \mathrm{D}$. Ge, "TEM investigation of contact loading induced phase transformation in silicon," Ph.D. thesis (Drexel University, 2004).

${ }^{48}$ M. S. R. N. Kiran, B. Haberl, J. S. Williams, and J. E. Bradby, J. Appl. Phys. 115, 113511(1-10) (2014).

${ }^{49}$ P. Pirouz, Scr. Metall. 21, 1463 (1987).

${ }^{50}$ P. Pirouz, U. Dahmen, K. H. Westmacott, and R. Chaim, Acta Metall. Mater. 38, 329 (1990).

${ }^{51}$ J. E. Bradby, J. S. Williams, J. W. Leung, M. V. Swain, and P. Munroe, Appl. Phys. Lett. 80, 2651 (2002).

${ }^{52}$ J. E. Bradby, J. S. Williams, J. W. Leung, M. V. Swain, and P. Munroe, J. Mater. Res. 16, 1500 (2001). 